\title{
Foot Anthropometric Profile of High School Students in Bandung
}

\author{
Imam Ramdhani Abdurrahman, ${ }^{1}$ Alwin Tahid, ${ }^{2}$ Fathurachman ${ }^{3}$ \\ ${ }^{1}$ Faculty of Medicine Universitas Padjadjaran, Indonesia, ${ }^{2}$ Department of Basic Medicine Faculty \\ of Medicine Universitas Padjadjaran, Indoneseia ${ }^{3}$ Department of Orthopaedics and Traumatology \\ Faculty of Medicine Universitas Padjadjaran/Dr. Hasan Sadikin General Hospital Bandung, \\ Indonesia
}

\section{Abstract}

Background: During the process of walking, the foot plays a role in supporting the body weight. Due to continously with stand weight, a person will experience foot pain aggravated by the use of improper shoe size. Foot anthropometric data acts as reference in the manufacture of orthotics and shoes with appropriate size, while Indonesia still does not have foot anthropometric data. The purpose of this study was to describe foot anthropometric data of high school students in Bandung in order to obtain good fitting shoes.

Methods: The study was performed using observational descriptive method on 81 students aged 16-18 years from three different senior high schools in different regions of Bandung in November 2014.

Results: The mean of foot and ankle anthropometry of senior high school students were $25.75 \mathrm{~cm}$ for Foot Length, $18.82 \mathrm{~cm}$ for Ball of Foot Length, $21.57 \mathrm{~cm}$ for Outside Ball of Foot Length, $9.70 \mathrm{~cm}$ for Foot Breadth Diagonal, 5.43 for Heel Breadth, $6.00 \mathrm{~cm}$ Navicular Height, $6.62 \mathrm{~cm}$ for Instep Height and 5.06 for Heel to Lateral Malleolus.

Conclusions: The anthropometric data help the footwear industry to determine the design and size for shoes in Indonesia.

Keywords: Anthropometry, ankle anthropometry, foot anthropometry, foot.

\section{Introduction}

Foot is the first structure of the musculoskeletal system that begin to grow at puberty. ${ }^{1}$ The human foot is composed of 26 bones and more than 30 synovial articulation. ${ }^{2}$ During walking, the foot supports the body to hold the weight of the body so, it can cause someone to feel pain in his feet due to that mechanism and exacerbated by using ill-fitting shoes. ${ }^{3}$ The use of narrow shoes is associated with the occurrence of corn on the finger-toe, bunion, and leg pain, while the use of shoes which is shorter than the foot is associated with deformities of toes. ${ }^{4}$

Comfortable shoes require the dimensions of the foot for the shoe by measuring the length, width and height of the foot.3 For example, Japan has its own standards to determine the size of the shoe by measuring foot length, girth, and width of the foot joint. ${ }^{5}$ However, Indonesia still does not yet have a foot anthropometric database to be used as reference in the development of footwear products. Moreover, the proper fit of shoes is important for diabetes patient to prevent complications. ${ }^{6}$

Due to its role in product development, each region should have an anthropometric database of its population as the anthropometric data of each area is different. Therefore, it is very important for a population to have their own anthropometric data in designing shoes to prevent incompatibility with users. ${ }^{7}$ In addition, the different anthropometric dimension of each population is influenced by age, race, region, and work that should be a reference in the provision of anthropometric data. $^{8}$

\section{Methods}

This study was conducted using the observational descriptive method. Data were

Correspondence: Imam Ramdhani Abdurrahman, Faculty of Medicine, Universitas Padjadjaran, Jalan Raya Bandung-Sumedang Km.21, Jatinangor, Sumedang, Indonesia, Email: imam.ramdhani93@yahoo.co.id 

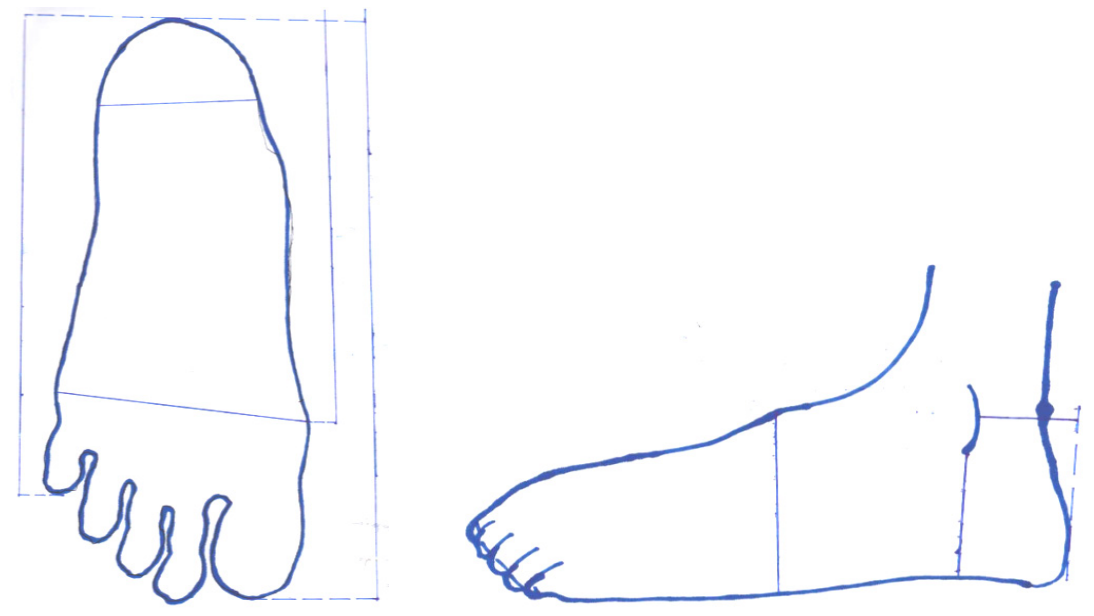

Figure 1 Eight Dimensions of Foot and Ankle

collected in November 2014 from three senior high schools in Bandung. The anthropometric data collection performed in this study was approved by the Health Research Ethic Committee, Faculty of Medicine, Universitas Padjadjaran. Samples were male senior high school students spread over three regions that were randomly selected from six regions in Bandung. The sample size was 81 people,s obtained by quantitative descriptive study formula with a precision value of $0.3 \mathrm{~cm}$. Samples included in the study were male students who met the inclusion criteria, aged
16-18 years and did not have a foot deformity. Furthermore, anthropometric measurements of the selected students were performed in a separate place from the classroom. After filling out the consent form, the students were instructed to sit with legs parallel to the floor then anthropometric measurements of foot and ankle were carried out. The measurement method used in this study was similar to previous studies.,

Eight dimensions of foot and ankle were measured comprising Foot Length, Ball of Foot Length, Outside Ball of Foot Length, Foot

Table 1 Age Distribution of Subjects ( $n=81)$

\begin{tabular}{|c|c|c|}
\hline Age group (years) & Percentage & Total \\
\hline 16 & 13.6 & 11 \\
\hline 17 & 72.8 & 59 \\
\hline 18 & 13.6 & 11 \\
\hline Total & 100 & 81 \\
\hline
\end{tabular}

Table 2 Foot Length Distribution by Age

\begin{tabular}{lcccccccc}
\hline \multirow{2}{*}{$\begin{array}{c}\text { Age } \\
\text { (years) }\end{array}$} & \multicolumn{7}{c}{ Foot length group (cm) } & \multirow{2}{*}{ Total } \\
\hline 16 & $\mathbf{2 3 - 2 4}$ & $\mathbf{2 4 - 2 5}$ & $\mathbf{2 5 - 2 6}$ & $\mathbf{2 6 - 2 7}$ & $\mathbf{2 7 - 2 8}$ & $\mathbf{2 8 - 2 9}$ & $\mathbf{2 9 - 3 0}$ & \\
\hline 1 & 1 & 1 & 0 & 4 & 3 & 1 & 1 & 11 \\
17 & 9 & 14 & 17 & 6 & 11 & 2 & 0 & 59 \\
18 & 0 & 2 & 5 & 4 & 0 & 0 & 0 & 11 \\
Total & 10 & 17 & 22 & 14 & 14 & 3 & 1 & 81 \\
\hline
\end{tabular}


Table 3 Foot Length Distribution by School

\begin{tabular}{lcccccccc}
\hline $\begin{array}{c}\text { Senior High } \\
\text { School }\end{array}$ & \multicolumn{7}{c}{ Foot length group (cm) } & \multirow{2}{*}{ Total } \\
\cline { 2 - 8 } & $\mathbf{2 3 - 2 4}$ & $\mathbf{2 4 - 2 5}$ & $\mathbf{2 5 - 2 6}$ & $\mathbf{2 6 - 2 7}$ & $\mathbf{2 7 - 2 8}$ & $\mathbf{2 8 - 2 9}$ & $\mathbf{2 9 - 3 0}$ & \\
\hline A & 1 & 4 & 7 & 7 & 2 & 2 & 0 & 11 \\
B & 3 & 4 & 7 & 2 & 10 & 1 & 1 & 59 \\
C & 6 & 9 & 8 & 5 & 2 & 0 & 0 & 11 \\
Total & 10 & 17 & 22 & 14 & 14 & 3 & 1 & 81 \\
\hline
\end{tabular}

Table 4 Mean (M), Standard Deviation (SD), Minimum (Min) and Maximum (Max) for Anthropometric Dimensions of the Foot and Ankle $(n=81)$, values in $\mathrm{cm}$

\begin{tabular}{lcccc}
\hline Foot Dimensions & M & SD & Min & Max \\
\hline Foot Length & 25.75 & 1.42 & 23.1 & 29.3 \\
Ball of Foot Length & 18.82 & 1.14 & 17 & 22.7 \\
Outside Ball of Foot Length & 21.57 & 1.13 & 19 & 23.7 \\
Foot Breadth Diagonal & 9.70 & 0.58 & 8.4 & 10.9 \\
Heel Breadth & 5.43 & 0.55 & 4.5 & 8.1 \\
Navicular Height & 6.00 & 0.58 & 4.8 & 7.7 \\
Instep Height & 6.62 & 0.51 & 5.4 & 8.5 \\
Heel to Lateral Malleolus & 5.06 & 0.65 & 3.5 & 6.7 \\
\hline
\end{tabular}

Breadth Diagonal, Heel Breadth, Navicular Height, Instep Height and Heel to Lateral Malleolus. Then those measurements were processed with a statistical software to find the mean, standard deviation, minimum and maximum values, the 5 th percentile, $50^{\text {th }}$ and $95^{\text {th }}$.

\section{Results}

Among 2259 intracerebral hemorrhagic
The age distribution of the sample included subjects from 16-18 years (Table 1). In this study a 16-years-old student was included in the longest foot length group (Table 2). While based on the region, one male student in $\mathrm{B}$ senior high school was included in the longest foot length group (Table 3).

The mean of foot and ankle anthropometry of senior high school students were 25.75 $\mathrm{cm}$ for Foot Length, $18.82 \mathrm{~cm}$ for Ball of Foot Length, $21.57 \mathrm{~cm}$ for Outside Ball of Foot

Table 5 Percentile for Anthropometric Dimensions of Foot and Ankle ( $\mathrm{n}=\mathbf{8 1})$, Values in $\mathbf{c m}$

\begin{tabular}{lccc}
\hline Foot Dimensions & 5th percentile & 50th percentile & 95th percentile \\
\hline Foot Length & 23.60 & 25.70 & 28.25 \\
Ball of Foot Length & 17.20 & 18.80 & 20.40 \\
Outside Ball of Foot Length & 19.42 & 21.70 & 23.29 \\
Foot Breadth Diagonal & 8.70 & 9.60 & 10.50 \\
Heel Breadth & 4.61 & 5.40 & 6.29 \\
Navicular Height & 5.21 & 5.90 & 7.18 \\
Instep Height & 5.81 & 6.60 & 7.78 \\
Heel to Lateral Malleolus & 4.21 & 5.00 & 6.30 \\
\hline
\end{tabular}


Length, $9.70 \mathrm{~cm}$ for Foot Breadth Diagonal, 5.43 for Heel Breadth, $6.00 \mathrm{~cm}$ Navicular Height, $6.62 \mathrm{~cm}$ for Instep Height and 5.06 for Heel to Lateral Malleolus (Table 4 and Table 5). Discussion

The results were displayed based on anthropometric measurements of foot and ankle in 81 senior high school students who met the inclusion criteria and were selected from several areas in Bandung.

The result showed a 16-years-old student with the longest foot length was included in the longest foot length group, and there was also one student at SMAN B who had the longest foot length in the group based on the region. It could be attributed to the differences in physical activities or nutritional factors such as in the anthropometric study conducted in India ${ }^{10}$ which shows that anthropometric differences could be due to regional differences.

Moreover, the foot length has an average value \pm SD $25.75 \pm 1.42$ with minimum and maximum values 23.1 and 29.3 (Table 4). In a study of 160 male students in Iran with ages ranging from 18 to 25 years, mean \pm SD values for the foot length are $26.5 \pm 1.31$ with a maximum value 30.5 and a minimum value of 23.1. ${ }^{3}$ There is a difference in the value of foot length between Iran and Indonesia, 26.5 and 25.75. In his study, Kanaani et al. ${ }^{3}$ states that the difference occurs due to the number of subjects with different ages and the use of different methods, besides using a ruler it is also coupled with a digital camera.

For mean $\pm S D$ values of the width of the foot is $9.70 \pm 0.58$ and minimum and maximum values of 8.4 and 10.9 (Table 4). In a study of 26 men with an age from 19-24 years in Hong Kong $^{11}$, the foot width value for mean \pm SD is $9.67 \pm 0.55$ and minimum and maximum values are 8.7 and 10.6. The value obtained by the study was not too much different, 9.70 to 9.67 .

Anthropometric values are useful in many ways, such as in product development of fitting shoes. However, basically theseanthropometric measurements are limited to foot measuring hence the development of products of fitted the shoes must also consider several factors, such as the design of the shoes. Hopefully, the results of this study would encourage other researchers to conduct this kind of research because Indonesia does not have a national standardization yet. Daily activities, age, and gender also need to be considered in further studies since those factors influence the variation in the dimensions of the foot based on studies conducted in other countries.
The limitation of this study was the use of a simple measuring instrument i.e. a ruler. Other instruments that can be used in the foot measurement are a digital caliper, digital gauges and first metatarsophalangeal joint indicators. ${ }^{12}$ For a further study, it is recommended to pay attention to several factors, such as age, gender, and physical activities.

\section{References}

1. Dimeglio A. Growth in pediatric orthopaedics. In: Lovell WW, Winter RB, Morrissy RT, Weinstein SL. Lovell and Winter's Pediatric Orthopaedics. 6th ed. Philadelphia: Lippincott Williams \& Wilkins; 2006. p. 59.

2. Oladipo G, Bob-Manuel I, Ezenatein G. Quantitative comparison of foot anthropometry under different weight bearing conditions amongst Nigerians. Internet J Bio Anthrop [Online Journal] 2009 [cited in 2014 June 21]. Available from: http://www.ispub.com.

3. Kanaani JM, Mortazavi SB, Khavanin A, Mirzai R, Rasulzadeh Y, Mansurizadeh M. Foot anthropometry of 18-25 years old Iranian male students. Asian J Sci Res. 2010;3(1):62-9.

4. Kurup H, Clark C, Dega R. Footwear and orthopaedics. J Foot Ankle Surg. 2012;18(2):79-83.

5. Agić A, Nikolić V, Mijović B. Foot anthropometry and morphology phenomena. Colleg antropol. 2006;30(4):815-21.

6. Schwarzkopf R, Perretta DJ, Russell TA, Sheskier SC. Foot and shoe size mismatch in three different New York City populations. J Foot Ankle Surg. 2011;50(4):391-4.

7. Ismaila S. Anthropometric data of hand, foot, ear of university students in Nigeria. Leonardo J Sci. 2009;15(8):15-20.

8. Luximon A, Luximon Y, Chao H. A Human Surface Prediction Model Based on Linear Anthropometry. Int J Adv Intell Sys. 2013;6(3):213-22.

9. Chaiwanichsiri D, Tantisiriwat N, Janchai S. Proper shoe sizes for Thai elderly. Foot. 2008;18(4):186-91.

10. Dewangan K, Prasanna Kumar G, Suja P, Choudhury M. Anthropometric dimensions of farm youth of the north eastern region of India. Int J Ind Ergonom. 2005;35(11):979-89.

11. Xiong S, Goonetilleke RS, Witana CP, Lee $\mathrm{Au}$ EY. Modelling foot height and foot shape-related dimensions. Ergonomics. 

Students in Bandung

2008;51(8):1272-89.

12. McPoil TG, Vicenzino B, Cornwall MW, Collins N. Can foot anthropometric measurements predict dynamic plantar surface contact area. J Foot Ankle Res. 2009;2(1):28. 